\title{
On the Legal Force and Application Scope of the Public Security Mediation
}

\author{
Jianwen Ma \\ Director of Guangzhou Key Research Base of Public Security \\ Professor of Guangdong Police College \\ 510232, Guangzhou, China \\ mmmkk@21cn.com
}

\begin{abstract}
Through the qualitative analysis of public security mediation, this study comes to such a conclusion that public security mediation agreement should be endowed with the same legal force as people's mediation agreement. By analyzing the application objects of public security mediation by the public security agency, this paper deems that public security mediation is neither conventional dispute among the people nor the entire civil dispute, but a specific scope between them. Therefore, we should adhere to the principle of voluntary mediation, tighten up mediation norms and strictly abide by the enforcement time limit of public security mediation. This paper proposes some new viewpoints concerning the legal force and application scope of the public security mediation.
\end{abstract} scope

Keywords-public security mediation; legal forc; application

The Article 9 in People's Republic of China Public Security Administrative Penalties Act stipulates that for the violation of security administration due to civil conflicts or property damage, public security agencies can handle this through mediation if the circumstances are relatively minor. In accordance with the Article 158 in Procedure for Public Security Bureau Administrative Cases, "if the parties have reached and fulfilled a settlement agreement through mediation, public security bureau shall no longer execute security punishment; if the parties fail to reach a agreement after mediation or one party goes back on the agreement before fulfillment, public security bureau shall execute security punishment on the offenders in accordance with the law." Thus this shows that the public security mediation agreement is not mandatory. In case that one or both parties refuse to fulfill the agreement, the public security mediation agreement will remain a dead letter and no progress has been made in this case, which not only wastes the law enforcement cost but greatly affects the judicial efficiency. In addition, where is the administrative boundary for mediating civil disputes by public security bureau? For the civil disputes violating the security administration, Public Security Administrative Penalties Act just provides a general statement "... fights or property damage and other actions that violates the security administration", but fails to make a clear demarcation of the jurisdiction scope. In the practice of public security administration, the mediation conducted by public security agencies at all levels is so inclusive and omnipotent that it almost covers all kinds of cases, which has gone far beyond the proper scope of legal norms. Therefore, clarifying the nature of the public security mediation, defining the boundary of public security mediation and grasping the real intention are necessary for both public security theory research and the law enforcement practice of public security administration.

\section{Qualitative Analysis of Public SECURITY MEDIATION}

Mediation refers to the activity that mediates organizations or individuals and urges the parties to reach reconciliation agreement voluntarily on the basis of equality and consultation by persuading and counseling in order to solve civil disputes. Mediation shall not contravene the laws, regulations and state policies, and must be conducted on the premise of the parties' own accord. The parties shall have the right to accept, refuse or terminate mediation, and mediator should respect the rights of the parties, and shall not prevent the parties to safeguard their own rights in accordance with the law by the means of arbitration, administration and judicature. The mediation right of public security agencies is derived from the law. Determining the nature of public security mediation is crucial to the parties' legal attitude towards public security mediation, the legal meaning of mediation agreement, whether there will be legal consequence or what kinds of legal consequences if one party goes back on the agreement before fulfillment, what remedy approaches can be taken and the executive force of public security mediation system. In accordance with the current laws and regulations, if the parties have reached and fulfilled a settlement agreement through mediation, the public security agency shall no longer execute security punishment; if the parties fail to reach a agreement after mediation or one party goes back on the agreement before fulfillment, the public security agency shall execute security punishment on the offenders in accordance with the law. The meaning of this Article can be deduced as the replacement between public security penalty power of public security bureau and private rights of the parties, in which the public power with complete and timely penalty is suspended to be used, a definite replacement invitation is offered to the parties. When the replacement offer is rejected, or the displacement conditions fail to be met to attain the purposes, the public power resumes its legal effects. Thus, it can be seen that the legal force of security mediation behavior and the settlement agreement is not clear.

The categories and ways of solving civil disputes are varied with their own advantages and disadvantages, which 
are complementary to each other in both functions and merits. To date, the settlement mechanisms for civil disputes in our country generally include the diversified approaches of contractual remedy, social remedy and public remedy. The typical way of contractual remedy is reconciliation, that is, both parties settle the disputes in a peaceful way through equal consultation and mutual compromise. The reconciliation agreement is similar to contract in nature and has mutual binding on both parties. Approaching from the dimension of the legal force of mediation, mediation can be divided into the mediation with implementation power, mediation that can apply for judicial recognition, mediation with contractual validity and mediation which depends completely on parties' voluntary fulfillment and so on. The agreement reached by court mediation in civil litigations in our country has the legal force of compulsory execution. Once the court mediation agreement is reached and delivered, the parties shall not break the agreement and they are deprived of the right of appeal. If the obligator does not perform its obligations in accordance with the mediation agreement, the beneficiary can apply to the court for compulsory execution. In accordance with Article 15 of Arbitration Law, the arbitration tribunal makes the mediation agreement or consent decree on the basis of the results of the mediation agreement and both of them have the same legal force. Although the administrative mediation has no legal force of compulsory execution, it is still legally binding on the parties. Like people's mediation, administrative mediation is conducted on a voluntary basis, in which the agreement has the same effect of contract that needs to be abided by the legal provisions for contract.

In the mediation system, the legal force of the mediation on the one hand depends on the pre-provisions of the system and on the other hand the autonomous will of the party. Although the nature of public security is not explicitly stipulated in the Public Security Administrative Penalties Act, public security mediation is in a complete accord with the characteristics of administrative mediation. The reasons are as follows: first, mediation conducted on the basis of the parties' will is the expression and confirmation of the parties' intention; second, the subject of public security mediation has its legality. The mediation by public security agencies is conducted according to the regulations of public security administrative penalty act; mediation by the traffic police is conducted according to the provisions of the road traffic accident treatment measures; third, the content of the public security mediation is legitimate. Public security mediation is carried out in accordance with the voluntary and legal principles, and any mandatory or oppressive mediation is illegal. As the principle of civil law is concerned, effective civil juristic is not necessarily legal, but legal civil juristic shall be valid. Fourth, public security mediation has the exclusive jurisdiction. Public security mediation which is designated to reconcile the disputes within its terms of reference in accordance with the provisions of laws and regulations has the exclusive jurisdiction. Fifth, the general procedures of public security mediation are accepting the disputes, putting forward mediation, implementing mediation program and terminating mediation, which are much the same as the administrative mediation and even judicial mediation.

The validity of the civil juristic acts should be equipped with the following three prerequisites: first, the actor has the relevant capacity for civil conduct; second, the intention expression is true; third, there is no violation of the law or the public interest. Any effective civil juristic action shall bear the corresponding civil legal responsibility. Therefore, the public security mediation by the public security authorities shall be legally binding and enjoy the same legal force as the people's mediation agreement. One party should fulfill the mediation as agreed if no fraud, coercion, opportunism, serious misrepresentations, obvious unfairness or any provisions violating the laws and regulations are found. If one party refuses to perform the obligations, the other can bring a suit in a people's court for the implementation of the agreement.

\section{The APPlication SCOPE FOR PUBlic SECURITY MEDiCATION CASES}

The provisions stipulated in the Public Security Administrative Penalties Act are "for the violation of security administration due to civil conflicts or property damage and etc, the public security bureau can handle this through mediation if the circumstances are relatively minor." The word "etc." is actually a misinterpretation if understood as including everything. The word "etc." takes the meanings of either unfinished enumeration or finishing up the enumeration in the laws and regulations and other documents. The application of public security cases is stipulated in the Procedure for Public Security Bureau Administrative Cases Article 158: "the public security agencies can handle the following administrative cases for violating the security administration with mediation: 1) fights caused by civil disputes which leads to slight injury; 2) property damage caused by civil disputes in minor circumstances; 3) other acts violating the security administration caused by civil disputes, if the circumstances are minor." For the definition of "disputes among the people", it is generally considered to consist of two elements: one is that the parties have acquaintance with each other in the daily life; the second is that the dispute may involve the property or non-property content, such as debt, house sites, third party involvement, walk, ventilation, lighting, etc. With respect to whether the public security cases caused by disputes among the people can be listed as public security mediation, the key boundary lies in - whether there are acts violating security administration that infringe personal rights or property rights. Other acts violating security administration caused by civil disputes, such as jeopardizing public security, disrupting public order and hindering the social management cannot be categorized as public security mediation.

The public security mediation is neither conventional dispute among the people nor the entire civil dispute, but a specific scope between them. This interpretation is mainly based on the following considerations:

First, the mediation system has become a governing strategy of modern society under the rule of law. China is 
acclaimed as the birthplace of various mediation systems adopted by the modern countries and the cradle of diversified cultures. As an approach to settle disputes, mediation with a long history and profound cultural foundation has been practiced in China for thousands of years, which has been constituted as China's excellent culture and the tradition of people's judicature. Since ancient times, Chinese culture has laid particular emphasis on the sense of dispute resolution, such as "harmony is the most precious", "quelling the litigation and preventing conflicts, "patching up quarrels and reconciling the parties concerned" and "preference mediation to disputes". It attaches importance to bring the official mediation, civil mediation and patriarchal mediation into a full play, take a broad and long-term view and pursue harmony in the dispute settlement. Practice has proven that the judicial system is far from omnipotent. The ideal objective of a harmonious society is neither to eliminate all kinds of contradictions and conflicts nor to neglect the existence of these contradictions and conflicts, but to build a scientific and reasonable legal and social mechanism to resolve contradictions and conflicts. Whether a society is harmonious and vigorous depends on whether the various mechanisms of resolving dispute are sound and perfect.

Second, the public security agencies shall undertake the responsibility of resolving major social contradictions. In recent years, the number of public security cases in our country has continued to rise, in which acts violating security administration due to disputes between family, neighbors and co-workers also see a sharp increase. Public security cases such as making noises, sending harmful information, disturbing others' normal life by raising animals, conniving animals to intimidate others, insult, slander, false accusation, invasion of privacy and stealing motor vehicles are increasing exponentially. If the scope of public security mediation is too narrow, it is inevitable that disputes cannot be promptly handled; however, if excessively widening the scope of mediation and replacing public security penalties with mediation, it will definitely weaken the crackdown of public security violators and degrade the severity of the cases. For instance, instigating trouble, hiring others to harm others, damaging public property to vent personal spite and other acts violating security administration by non-civil disputes have gone beyond the mediation scope stipulated in the Public Security Administrative Penalties Act, which will lead people to misinterpret the Law and even presume that they shall not bear any legal liability as long as compensating the economic loss.

In accordance with the Article 9 of Public Security Administrative Penalties in our country, social conflicts in minor severity are categorized as the administrative mediation, while other fierce social conflicts are allocated into the category of administrative penalties and even criminal sanctions, which can not only economize the limited enforcement resources but also ensure the timely resolution of social conflicts. In the law enforcement practice, the functional departments concerned should strengthen the supervision and inspection over the grass- roots public security agencies, and incorporate the quality of public security mediation into the range of the law enforcement quality evaluation to eliminate the unnecessary mediation or mediation out of scope.

\section{TO TIGHTEN UP MEDiATION NORMS IN PUBLIC SECURITY MEDIATION}

At present, there exist the noticeable disadvantages and limitations in the public security mediation system which restricts the scale effect of public security mediation system in our country and fails to meet the need of building a harmonious society. Currently, the local police stations have to pay high attention to the following aspects in handling public security cases:

1. To strictly abide by the principle of voluntary mediation. Public security mediation must respect the will of the parties, enable them to participate in mediation under the premise of voluntariness and reach the agreement on the basis of mutual understanding. The public security agencies should serve as an organizer and facilitator whose behavior does not have coerciveness. They should act as the outside force to persuade, guide, propitiate and coordinate in the whole process, while the final decision is based on the true intention of both parties without any threat or fraud.

2. To tighten up the mediation norms. Prompt investigation is the need to find out the case facts, distinguish right from wrong, clarify the responsibilities of the parties concerned, and ensure the fairness and legitimacy of public security mediation results as well as an important link to avoid illegal procedure. In mediating public security cases, some grassroots policemen fail to carry out a timely and thorough investigation to gather up sufficient case materials. For lack of careful investigation, they are unable convince both parties with facts and evidence, which causes the low rate of success. Once a mediation agreement is unable to be reached, a prompt and effective verdict is difficult to be made due to the unclear investigation of the case facts and insufficient evidence. Some departments have handled many mediation cases, while only few mediation files can be found. The public security agencies should strictly abide by the requirements of "Standardization Construction of Law Enforcement" and attaches great importance to organize and archive mediation files.

3. To strictly implement the enforcement time limit of public security mediation. The Public Security Mediation Work Specification issued by the Ministry of Public security stipulates that "Public security mediation is general onetime thing and can be increased to twice when necessary. Cases applied to public security mediation should be handled within 3 working days after acceptance if there is no need for relevant identification; cases should be mediated within 3 working days after the completion of relevant identification. For cases fail to reach a mediation agreement for the first time, a second mediation is needed and should be completed within 7 working days after the first mediation

" In practice, the departments concerned should complete the public security mediation cases within the given time in strict accordance with the regulations stipulated by the public security bureau. For the failed mediation or un- 
fulfillment of mediation agreement, security punishment has to be made on the relevant violators within the legal time limit in order to safeguard the legitimate rights and interests of the victims. On legislation, there should be a restriction on the time limit of public security mediation, which will protect the interests of the public, improve the administrative efficiency to prevent the backlog of cases, and meanwhile avoid the arbitrariness of procedures of applicable security mediation.

\section{REFERENCES}

[1] Huang Jing. On the Mediation System of Civil Disputes by the Public Security Agency. Collected Papers on Social Management Innovation, Guangzhou Public Security Bureau, 2011, vol. p.165

[2] Chen Jiaxun, Et al. Investigation and Handling of Public Security Cases [M]. Beijing: Chinese People's Public Security University Press, 2009

[3] Wu Zhongmin. Major Social Contradictions in China's Reform Process [M]. Beijing: Party School of the CPC Central Committee Publishing House. 